\title{
Early-life cockroach allergen and polycyclic aromatic hydrocarbon exposures predict cockroach sensitization among inner-city children
}

\author{
Matthew S. Perzanowski, PhD ${ }^{1,2}$, Ginger L. Chew, $\mathrm{ScD}^{1,2}$, Adnan Divjan ${ }^{1,2}$, Kyung Hwa \\ Jung $^{1,3}$, Robert Ridder ${ }^{1,3}$, Deliang Tang, PhD ${ }^{1,2}$, Diurka Diaz, MA ${ }^{1,2}$, Inge F. Goldstein, \\ DrPH $^{1,4}$, Patrick L. Kinney, ScD ${ }^{1,2}$, Andrew G. Rundle, Dr.PH ${ }^{1,4}$, David E. Camann ${ }^{5}$, \\ Frederica P. Perera, DrPH ${ }^{1,2}$, and Rachel L. Miller, MD ${ }^{1,2,3}$ \\ ${ }^{1}$ Columbia Center for Children's Environmental Health (CCCEH), Columbia University College of \\ Physicians and Surgeons, New York, NY \\ ${ }^{2}$ Department of Environmental Health Sciences, Mailman School of Public Health, Columbia \\ University College of Physicians and Surgeons, New York, NY \\ ${ }^{3}$ Division of Pulmonary, Allergy, Critical Care Medicine, Department of Medicine, Columbia \\ University College of Physicians and Surgeons, New York, NY \\ ${ }^{4}$ Department of Epidemiology, Mailman School of Public Health, Columbia University, New York, \\ NY \\ ${ }^{5}$ Southwest Research Institute, San Antonio, Texas
}

\begin{abstract}
Background-Sensitization to cockroach is one of the strongest identified risk factors for greater asthma morbidity in low-income, urban communities; however, the timing of exposures relevant to development of sensitization has not been elucidated fully. Further, exposure to combustion byproducts, including polycyclic aromatic hydrocarbons (PAHs), may augment the development of allergic sensitization.
\end{abstract}

Objective-To test the hypotheses that domestic cockroach allergen measured prenatally would predict cockroach sensitization in early childhood, and that this association would be greater for children exposed to higher concentrations of PAHs.

Methods-Dominican and African-American pregnant women living in NYC were enrolled. In the third trimester, expectant mothers wore personal air samplers for measurement of 8 nonvolatile PAHs and the semi-volatile PAH pyrene, and dust was collected from homes for allergen measurement. Glutathione-s-transferase $\mathrm{mu}$ (GSTM1) gene polymorphisms were measured in children. Allergen-specific IgE was measured from the children at ages 2, 3, 5 and 7 years.

Results-Bla g2 in prenatal kitchen dust predicted cockroach sensitization at age 5-7 years [adjusted relative risk $(\mathrm{RR}) 1.15 ; \mathrm{P}=0.001 ; \mathrm{n}=349$ ]. The association was observed only among

C2012 American Academy of Allergy, Asthma and Immunology. Published by Mosby, Inc. All rights reserved.

Corresponding author: Matthew S. Perzanowski, Ph.D., Department of Environmental Health Sciences, Mailman School of Public Health, Columbia University, 722 West $168^{\text {th }}$ Street, $11^{\text {th }}$ floor, New York, New York 10032, Telephone \# (212) 305-3465, Fax \# (212)305-4012, mp2217@ columbia.edu.

Publisher's Disclaimer: This is a PDF file of an unedited manuscript that has been accepted for publication. As a service to our customers we are providing this early version of the manuscript. The manuscript will undergo copyediting, typesetting, and review of the resulting proof before it is published in its final citable form. Please note that during the production process errors may be discovered which could affect the content, and all legal disclaimers that apply to the journal pertain. 
children above [RR 1.22; $\mathrm{P}=0.001]$, but not below [RR 1.07; $\mathrm{P}=0.24]$ median sum of 8 nonvolatile PAH levels. The association was most pronounced among children with higher PAH and null in the GSTM1 gene [RR 1.54; $\mathrm{P}=0.001]$.

Conclusions-Prenatal exposure to cockroach allergen was associated with a greater risk of developing allergic sensitization. This risk was increased by exposure to nonvolatile PAHs, with children null for the GSTM1 mutation particularly vulnerable.

\section{Key messages}

- Domestic exposure to cockroach allergen measured prenatally predicted sensitization to cockroach at age 5-7 years.

- Cockroach allergen predicted sensitization only among children also exposed to higher levels of airborne non-volatile polycyclic aromatic hydrocarbons, indicating that these combustion byproducts may act as adjuvants in the development of cockroach sensitization in urban environments.

- These findings suggest that targeting either allergen or combustion sources with primary prevention could be successful in reducing the development of cockroach sensitization.

\section{Keywords}

Bla g2; cockroach; polycyclic aromatic hydrocarbon; IgE; allergy; inner-city; GSTM; GSTP

\section{INTRODUCTION}

Sensitization to cockroach allergens is one of the strongest identified risks for greater asthma morbidity in low-income urban populations (1). While several studies among preschool and school-age children have demonstrated associations between cockroach allergen measured in the home and sensitization $(2,3)$, studies have not yet demonstrated prospectively whether cockroach allergen in a child's house dust predicts development of sensitization. Understanding whether exposure to cockroach allergen in the prenatal and early postnatal time period lead to sensitization could inform primary prevention interventions.

Emerging evidence suggests that environmental co-exposures in addition to allergens, including microbial products and diesel exhaust particles (DEP), could modify the risk for developing allergic sensitization $(4,5)$. For example, Diaz-Sanchez et al. demonstrated in human in vivo experiments that DEP can act as adjuvants to promote sensitization to novel allergens and enhance the T-helper cell type 2 (Th2) response to established sensitization (6, 7). Like cockroach allergen, DEP and other combustion products are ubiquitous exposures in urban communities, beginning prenatally (8-10). One class of combustion byproducts found in DEP, polycyclic aromatic hydrocarbons (PAHs), has been investigated extensively for its contribution to the development of cancer $(11,12)$. We and others also demonstrated associations between PAHs and respiratory outcomes, and these associations appeared to differ with exposure to a composite variable of 8 highly correlated non-volatile PAHs $\left(\Sigma_{8} \mathrm{PAH}_{\text {nonvolatile }}\right)$ as compared to exposure to the less-well correlated, semi-volatile pyrene (13-15).

Common polymorphisms in the glutathione-s-transferases mu (GSTM) and pi (GSTP) have been shown to alter the conjugation kinetics of PAHs (16-18). These same polymorphisms appear to modify the adjuvant effect of DEP on allergic sensitization (19) and have been 
associated with other allergic disease related health outcomes (e.g., lung function, asthma) (20-23). However, whether these polymorphisms modify the effect of PAH on allergic sensitization still needs to be elucidated.

We hypothesized that domestic cockroach allergen measured prenatally would predict cockroach sensitization in early childhood, and that the magnitude of this association would be greater for children also exposed prenatally to higher levels of PAHs. We tested this hypothesis in a well-characterized birth cohort study of children of women of AfricanAmerican and Dominican ethnicity living low-income neighborhoods in NYC. We also tested whether the magnitude of the association between Bla g2, PAH and sensitization would be greater among children with the polymorphisms in GSTM and GSTP genes.

\section{METHODS}

As part of the Columbia Center for Children's Environmental Health (CCCEH), 727 nonsmoking pregnant African-American or Dominican women between the ages 18 and 35 who were living in Northern Manhattan and the South Bronx were enrolled $(8,10,24)$. Women with a history of asthma or allergies were not recruited preferentially. Detailed questionnaires were administered to the participants before the child was born. Environmental tobacco smoke (ETS) exposure during pregnancy was assessed by questionnaire. The children were followed prospectively (Figure 1). Columbia University's Institutional Review Board approved this study.

\section{Allergen exposures}

Bed and kitchen dust samples were collected from the participant's home during the third trimester and again when the child was 1, 3 and 5 years old (24). Dust samples were extracted without prior sieving, but large debris was removed. Kitchen and bed samples were assayed for Bla g2 (Indoor Biotechnologies, Charlottesville, VA) and mouse urinary protein (MUP) and bed samples for Der f1 by enzyme-linked-immunosorbant assay as described (24). Estimation of Bla g2 and Der f1 concentrations were based on the universal allergen standard curve, and thus comparisons with our results published prior to 2011 and those of other studies not using the universal allergen standard will require conversions as described $(3,25)$. For results below the limit of detection, values of half of the limit of detection were used in analyses.

\section{PAH measures}

Personal air sampling was conducted for the mothers during the third trimester of pregnancy as described $(10,13)$. Briefly, women wore a small backpack during waking hours and placed the sampler near their bed at night. Air was sampled for 48 hours at $4 \mathrm{~L} / \mathrm{min}$. Particulate matter 2.5 microns in diameter or smaller (PM2.5) was collected on a quartz microfiber filter and semi-volatile components were collected on polyurethanes foam (PUF) plug backups. Filters and PUFs were extracted together and analyzed by gas chromatography/mass spectrometry at Southwest Research Institute for benz(a)anthracene, benzo(b)fluoranthene, benzo(k)fluoranthene, benzo(ghi)perylene, benzo(a)pyrene, chrysene/ isochrysene, dibenz(a,h)anthracene, indeno(1,2,3-cd)pyrene and pyrene (26).

\section{Immunoglobulin (Ig) E}

IgE antibodies to cockroach, mouse, $D$. farinae and cat were measured in serum collected from children at ages 2, 3, 5 and 7 years. As described previously, 40 of the initial samples collected at ages 2 and 3 were assayed by Fluorescence Allergosorbent Test (Bio-Whitaker, Walkersville, MD) and all of the subsequent samples by ImmunoCAP (ThermoFisher, Upsalla, Sweden) $(27,28)$. A subset of samples was analyzed by both methods to confirm 
concordance (data not shown). Specific IgE $\geq 0.35$ I.U./ml was considered positive. Children with at least one positive specific IgE at ages 5 or 7 were considered positive at age $5-7$, and a similar variable was created for age $2-3$.

\section{GSTM and GSTP genotyping}

DNA was isolated from the child's cord blood cells or at a later age (between age 2-5 years) from peripheral blood mononuclear cells. The deletion of GSTM1 was assessed by Multiplex PCR system (29). Children who were homozygous (+/+) or heterozygous (-/+) for GSTM1 were classified as GSTM1 positive, and those who were homozygous deleted $(-/-)$ were classified as GSTM1 null. Polymorphisms in the GSTP1 (Ile105Val, rs1695) were assessed with the use of the ABI 7500 System in the TaqMan genotyping assay with primers and probes obtained from ABI. GST-P1 primers were GST-P1-F CCTGGTGGACATGGTGAATGAC; GST-P1-R CAGATGCTCACATAGTTGGTGTAGA.

\section{Data analyses and statistics}

Analyses were restricted to children who had complete data on PAH and Bla g2 measured prenatally and IgE measured at age 5 and/or 7 years. The greatest Bla g2 concentration measured in kitchen dust at age 1, 3 or 5 was assigned as the postnatal Bla g2. Allergen and PAH levels were approximately natural log-normally distributed; natural log-transformed variables were used in analyses. For visualization of the associations between allergen exposure and allergic sensitization logistic regression curves were plotted. For multivariable analyses of these associations relative risks (RR) with 95\% C.I. were calculated using binomial regressions in generalized estimating equations. The potential cofounders and covariates sex, race/ethnicity, maternal asthma, material hardship, prenatal ETS, birth order and age of child at IgE measurement were included in all multivariable models.

Multiplicative interaction terms were included in the multivariable models to test for effect modification. As we have reported previously, the eight non-volatile PAHs showed a high degree of correlation with each other, but the semi-volatile pyrene does not correlate well with these other PAHs (13). Therefore, in keeping with the previous analytical strategy, PAH levels were analyzed as the sum of eight individual non-volatile PAHs $\left(\Sigma_{8} \mathrm{PAH}_{\text {nonvolatile }}\right)$ and, separately, pyrene. A previously defined home heating season variable was included in all models that included PAH or pyrene (26). Data were analyzed in SPSS version 17 (Chicago, IL) and visualized in R version 2.14.0.

\section{RESULTS}

There were $\mathrm{n}=349$ children with measurements for prenatal Bla g2, prenatal PAH, and IgE measured at least once between ages 5-7 years (See Figure E1 in this articles Online Repository at www.jacionline.org). Of these, $\mathrm{n}=317$ children also had a Bla g2 measured at least once in kitchen dust between ages 1-5 years. The demographics of the mothers are reported in Table I. When comparing children who were included in the analyses to those who were enrolled, but excluded from these analyses, there were no statistically significant differences, except a slightly higher frequency of African-Americans and women receiving Medicaid (Table E1, Online Repository).

\section{Prenatal indoor allergen measures and development of sensitization}

There was no correlation between Bla g2 in kitchen dust and non-volatile $\Sigma_{8} \mathrm{PAH}_{\text {nonvolatile }}(\mathrm{r}$ $=0.003, \mathrm{P}=0.95$; Figure E2, online repository) or pyrene $(\mathrm{r}=0.060, \mathrm{P}=0.20)$ measured in the air prenatally. Bla g2 measured in kitchen dust prenatally and the highest postnatal measure available between age $1-5$ years correlated minimally $(r=0.15, P=0.007$, Figure 
E2). Bla g2 measured in the kitchen and bed dust prenatally correlated $(\mathrm{r}=0.49, \mathrm{P}<0.001)$, as described previously (24).

The prevalence of IgE to cockroach increased as the children aged from $2(13 / 262 ; 5.0 \%)$ to $3(24 / 269 ; 8.9 \%)$ to $5(66 / 324 ; 20.4 \%)$ to $7(82 / 264 ; 31.1 \%)$ years. In univariate analyses (Figure 2) and after controlling for potential confounders, prenatal cockroach allergen was associated with cockroach sensitization at age 5-7 [RR 1.15; 95\% CI 1.06, 1.24; P = 0.001]. A similar, although statistically non-significant trend was observed for sensitization at age 2-3 [RR 1.09; 95\% CI 0.93, 1.28; $\mathrm{P}=0.28$ ]. Among the 317 children with postnatal allergen exposure, in multivariable analyses both prenatal [RR $1.1195 \%$ CI 1.03, 1.19; $\mathrm{P}=0.009$ ] and postnatal [RR 1.120; 95\% CI 1.10, 1.31; P < 0.001] kitchen Bla g2 independently predicted age $5-7$ cockroach sensitization (same model). Prenatal Bla g2 in bed dust was not associated with sensitization at age 5-7 [RR $1.06 ; 95 \% 0.95,1.17 ; \mathrm{P}=0.32]$. While there appeared to be modest effect modification of the association between Bla g2 exposure and sensitization by race/ethnicity, sex and maternal asthma (Table II), none of these interaction terms approached statistical significance (all $P_{\text {interactions }}>0.20$ ). Among the subset of children for whom we had measured maternal total $\operatorname{IgE},(n=229)$ there was no effect modification by high (>100 IU/ml) maternal total IgE (data not shown). Inclusion of the number of people living in the home (to assess crowding) in these models did not alter the main effect estimates.

Mouse sensitization also increased between ages 2-3 (7.8\%) and 5-7 (14.3\%), but was not associated with mouse (MUP) allergen exposure measured in prenatal kitchen or bed dust (all multivariable $\mathrm{P}>=0.38$ ). Sensitization to $D$. farinae increased between ages $2-3(4.1 \%)$ and 5-7 (16.0\%). Geometric mean Der f1 allergen in prenatal bed dust was significantly higher among children sensitized to dust mite at age 2-3 as compared with those who were not $(\mathrm{P}=0.001)$; however, the multivariable model did not reach convergence. There was no association between prenatal Der f1 exposure and sensitization at age 5-7 years [RR 0.98; $95 \%$ CI $0.83-1.15 ; \mathrm{P}=0.78]$.

\section{Effect modification by PAHs}

There was no association between $\Sigma_{8} \mathrm{PAH}_{\text {nonvolatile }}$ and sensitization to cockroach at age 2$3(\mathrm{P}=0.13)$ or $5-7(\mathrm{P}=0.33)$ or mouse or dust mite at these ages, nor were there any associations between pyrene and sensitization. In bivariate analyses, Bla g2 in prenatal kitchen dust was associated with sensitization to cockroach at age 2-3 and 5-7 (Figure 3) among the children with higher (above median) prenatal measures of $\Sigma_{8} \mathrm{PAH}_{\text {nonvolatile, but }}$ not those with lower $\Sigma_{8} \mathrm{PAH}_{\text {nonvolatile exposure. Similarly, in multivariable models prenatal }}$ kitchen Bla g2 was associated with sensitization to cockroach at age 2-3 among children with higher [RR 1.42; 95\% CI 1.14-1.77; P = 0.002], but not lower [RR 0.93; 95\% CI 0.75$1.15 ; \mathrm{P}=0.49] \Sigma_{8} \mathrm{PAH}_{\text {nonvolatile }}$ exposure [Pinteraction $=0.009$ ]. In similar models, sensitization to cockroach at age 5-7 was associated with Bla g2 among children with higher [RR 1.22; CI 1.08, 1.36; P = 0.001], but not lower [RR 1.07; CI 0.96, 1.20; P = 0.24] prenatal $\Sigma_{8} \mathrm{PAH}_{\text {nonvolatile }}$ exposure $\left[\mathrm{P}_{\text {interaction }}=0.088\right]$. Among the children with higher prenatal $\Sigma_{8} \mathrm{PAH}_{\text {nonvolatile }}$ exposure, the association between prenatal Bla g2 exposure and sensitization at age 5-7 held after adjustment for postnatal Bla g2 exposure (RR 1.17; 95\% CI 1.02-1.35; P = 0.023). In sensitivity analyses, similar associations were observed when $\Sigma_{8} \mathrm{PAH}_{\text {nonvolatile }}$ exposure dichotomization considered whether measurement was conducted in the heating or non-heating season (data not shown).

There was no effect modification of the association between prenatal Bla g2 and sensitization by prenatal pyrene exposure in univariate or multivariable analyses (Figure E3, Online Repository). 


\section{Effect modification by polymorphisms in GSTM and GSTP}

There were no differences in sex, maternal asthma, sensitization to cockroach, or Bla g2 or PAH concentrations between children with and without the GSTM and GSTP genes studied (Table E2, Online Repository). There was a modest difference in the frequency of the GSTP polymorphism but not the GSTM deletion by race/ethnicity.

The association between Bla g2 and sensitization among children with higher $\Sigma_{8} \mathrm{PAH}_{\text {nonvolatile }}$ appeared to be of greater magnitude among those children null for GSTM1 gene as compared to those with the gene in univariate analyses (Figure 4). In multivariable analyses, among children with higher prenatal $\Sigma_{8} \mathrm{PAH}_{\text {nonvolatile, }}$ Bla g2 was associated (borderline) with cockroach sensitization at age 5-7 among the children with GSTM ( $\mathrm{n}=$ 114, RR 1.15; 95\% CI 1.00-1.33; P = 0.046). The RR was greater among the children without the GSTM $(\mathrm{n}=38$; RR 1.54; 95\% CI 1.18, 2.01; P = 0.001) and the interaction term (Bla g2 $\times$ GSTM) was $\mathrm{P}=0.12$. We did not observe effect modification by polymorphisms in GSTP (Figure E4, Online Repository).

\section{DISCUSSION}

In this inner-city birth cohort, cockroach allergen measured in kitchen dust during pregnancy predicted cockroach sensitization by age 5-7, even after controlling for cockroach allergen measured at ages $1-5$ years. The association was modified by airborne prenatal nonvolatile PAH concentrations. Children lacking the common GSTM1 gene polymorphism appeared to be more susceptible to sensitization with the combined cockroach allergen and PAH exposure.

These findings build on associations between domestic cockroach allergen concentrations and sensitization observed in cross-sectional studies among 4-7 year old children in NYC $(2,3)$. But these findings are novel because they demonstrate that cockroach allergen exposure at earlier ages, prenatally or early postnatal, is contributing to sensitization development at later ages. Given that both prenatal and age 1-5 cockroach allergens were associated independently with sensitization, it seems that exposure throughout early childhood can contribute to sensitization. The modest correlation we observed between prenatal and postnatal cockroach allergen exposure was not as strong as has been observed for dust mite and cat over similar time periods(31), which may reflect changes in infestation. This study design did not allow for the resolution of whether the relevant exposures were in utero or early postnatal (e.g., first year), because we did not measure allergens or PAHs immediately after the child was born. Still, it is unlikely that such measures would have been sufficiently variable to evaluate these exposure times independently (i.e., not many mothers changed residence). Previously, we published findings from this cohort showing antigenspecific cord blood mononuclear cell responses, including to cockroach allergens, that offer evidence of immune priming in utero (8); however, the cord blood proliferative responses did not predict specific IgE development to cockroach at age 5 (28). Collectively, our findings with cockroach and those from prospective studies of dust mite exposure (32-34) demonstrated that path to allergen-specific sensitization can begin early in life.

Exposure to non-volatile PAH modified the risk for sensitization with cockroach allergen exposure. Evidence for associations between combustion byproducts and allergic sensitization to inhalant allergens initially came from studies observing a higher prevalence of aeroallergen sensitization in cities with higher air pollution (i.e. in East Germany) (35). More direct evidence came from human in vivo studies in which diesel exhaust particles (DEP) acted as adjuvants to IgE production to keyhole limpet hemocyanin (KLH) measured in subjects' noses after nasal co-exposure to DEP and KLH (7). Studies in mice further advanced these findings, demonstrating that exposure to DEP during sensitization to 
Aspergillus fumigatus was associated with a greater IgE response than without DEP, and corresponding altered DNA methylation of interferon gamma and interleukin-4 (36). Together, these studies indicate that the higher combustion byproduct and cockroach allergen exposures seen in lower income urban communities $(3,37)$ are acting synergistically, leading to greater risk of sensitization. However based on the previous studies, it seems that this effect of increased sensitization in response to combustion byproducts is due to a non-specific effect of increasing sensitization to any allergen, not specifically cockroach.

The finding of associations with the $\Sigma_{8} \mathrm{PAH}_{\text {nonvolatile }}$ but not pyrene suggest that a nonvolatile PAH may be the compounds in DEP that act as an adjuvant; however, we cannot exclude the possibility that $\mathrm{E}_{8} \mathrm{PAH}_{\text {nonvolatile }}$ concentrations correlate with other, unmeasured compounds that act as the adjuvant. DEP may act as adjuvants by activating dendritic cells (DCs), increasing their maturation and expression of T-cell co-stimulatory molecules (38). In mice, exposure to pollutants from DEP elicited a greater T-helper cell type 2 (Th2) response, uptake of antigen by DCs and expression of the co-stimulatory molecules than exposure to particulates from automobile exhaust with lower DEP $(39,40)$. Also, semivolatile PAHs like pyrene have primarily indoor sources, while non-volatile PAHs have primarily outdoor combustion sources (41). In experimental studies, pyrene has demonstrated both pro and non-allergic immune responses (42-44). Also, non-volatile PAHs can travel in air on particles while the semi-volatile pyrene could travel as a gas, possibly affecting their inhalation into the distal airways. Hence, combustion source, exposure dynamics in the airways, and immunostimulatory capabilities all could contribute to differences seen with exposure to non-volatile PAHs versus the semi-volatile pyrene.

These findings support those from the human in vivo models of KLH sensitization suggesting that individuals null in the GSTM1 gene may be at increased susceptibility for the adjuvant effect of combustion byproducts on sensitization. Like other GSTs, GSTM catalyzes the binding of glutathione with reactive electrophiles, including those from PAHs (45). In occupational studies adults null as compared with those with the GSTM1 gene had higher PAH DNA adduct concentrations (e.g., (Benzo(a)pyrene diol epoxide) in lymphocytes, indicating that the GSTM1 gene increases metabolism of PAHs from environmental sources $(45,46)$. Therefore, if non-volatile PAH are acting as adjuvants, individuals with the GSTM1 gene may be better able to detoxify the relevant PAHs and decrease the impact of these exposures on development of sensitization.

We did not observe consistent associations between mouse or dust mite allergen exposure and sensitization. The lack of an association with domestic mouse allergen is consistent with our observations in two cross-sectional studies of children living in NYC $(2,3)$. It may be related to important exposure differences among mouse, cockroach and dust mite allergens including the aerodynamic properties of the particles that carry the allergens (47) and exposure in schools (48). The lack of a consistent association between prenatal dust mite allergen and sensitization was not consistent with findings from several prospective studies (32-34); however, only $12 \%$ and $9 \%$ of children in this study had dust mite allergen above the cut-points described in studies by Lau et al. and Sporik et al., respectively $(32,33)$. An association between dust mite exposure and sensitization was observed in a cross-sectional study of 7-8 year-olds from a different population in NYC that included children living in freestanding homes where dust mite allergen concentrations were greater than in apartment buildings $(3,49)$.

Interventions to reduce cockroach allergens are acknowledged to be difficult in the multifamily apartment buildings typically found in cities (50). Some promise of successful allergen reduction with intervention was demonstrated by the Inner-city Asthma Study (50) 
and from a building-wide implementation of integrated pest management conducted by the NYC Department of Health and Mental Hygiene and the NYC Housing Authority (the largest public housing authority in North America) (51). Our data seem to suggest, however, that allergen needs to be reduced throughout early childhood. Reduction in PAH exposures mostly require large-scale public health initiatives. The two principal sources of combustion byproducts in NYC homes, including PAHs, are diesel trucks and residential burning of residual fuel oil in boilers $(10,26,37,52)$. Recently-enacted regulations to eliminate residual oil burning in NYC could lead to some reduction in the sources of PAHs. Further public health interventions should include reduction of pollution from diesel combustion sources.

This study had several limitations. We only had complete data for these analyses on approximately half of those children originally enrolled. However, the children included in the analyses did not differ significantly from those not included in key variables, including $\mathrm{PAH}$ and Bla g2 exposures. The decreased samples size may have limited our power to detect associations between the other allergens and sensitization or effect modification of these associations by PAH exposure. Also, it reduced the sample size for the models that included adjustment of postnatal Bla g2 exposure and the stratification by PAH and genotype. While estimates of statistical significance for some of these interaction terms fell into range that included $\mathrm{P}$ values $>0.05$, multiplicative interaction terms were tested and additive interactions could be considered biologically relevant. Still, the main association between Bla g2 and sensitization remained statistically significant in the children exposed to higher PAH and among those, the children null for GSTM1. We did not assess the association between exposure to seasonal aeroallergens and sensitization, which also might be modified by PAH exposure. We only assessed PAH exposure with a 48-hour sampling period; however, we have previously demonstrated a good correlation between this measurement and longer-term residential sampling in the subsequent months of pregnancy (53).

In summary, these findings offer further evidence that exposure to cockroach allergens and combustion byproducts contribute to allergic sensitization. To our knowledge, this study is the first to observe an interaction between domestic allergen exposure and PAHs on development of allergen specific IgE. The mechanisms may begin prenatally, signifying that the first step in the atopic march may occur early in the maturation of the immune system. Given the well-established link between cockroach sensitization and asthma morbidity (27, 54), these findings suggest that early-life interventions on either cockroach allergen or combustion byproducts could reduce sensitization and thus asthma morbidity in urban communities.

\section{Acknowledgments}

The authors would like to thank the participating mothers and children. This work would not have been possible without the hard work and dedication of the research workers and field technicians.

Supported by: This study was supported by the National Institute of Environmental Health Sciences (NIEHS) (grant \#'s P01 ES09600, 5 RO1 ES08977, R01ES13163, RO1ES11158, P30 ES009089, P50ES015905, R03 ES013308), the U.S. Environmental Protection Agency (EPA) (grant \#'s R827027, RD832141, RD834509), Bauman Family Foundation, Gladys \& Roland Harriman Foundation, New York Community Trust, Educational Foundation of America, The New York Times Company Foundation, The Schmidt Family Foundation, The Johnson Family Foundation, Rockefeller Financial Services, Horace W. Goldsmith Foundation, Beldon Fund, The John Merck Fund, and V. Kann Rasmussen Foundation. 


\section{Abbreviations}

$\Sigma_{8} \mathbf{P A H}_{\text {nonvolatile }}$

Bla g2

ССCEH

Der f1

ETS

GSTM1

GSTP1

MUP

NYC

PAH

RR
Sum of 8 non-volatile PAHs

A major allergen from the German cockroach Blatella germanica

Columbia's Center for Children's Environmental Health

A major allergen from the dust mite Dermataphagoides farinae

Environmental tobacco smoke

A common polymorphism in the glutathione-s-transferase $m u$ gene

A common polymorphism in the glutathione-s-transferase pi gene

Mouse Urinary Protein

New York City

Polycyclic aromatic hydrocarbon

Relative risk

\section{References}

1. Togias A, Fenton MJ, Gergen PJ, Rotrosen D, Fauci AS. Asthma in the inner city: the perspective of the National Institute of Allergy and Infectious Diseases. J Allergy Clin Immunol. 2010; 125:540-4. [PubMed: 20226290]

2. Chew GL, Perzanowski MS, Canfield SM, Goldstein IF, Mellins RB, Hoepner LA, AshbyThompson M, Jacobson JS. Cockroach allergen levels and associations with cockroach-specific IgE. J Allergy Clin Immunol. 2008; 121:240-5. [PubMed: 17936887]

3. Olmedo O, Goldstein IF, Acosta L, Divjan A, Rundle AG, Chew GL, Mellins RB, Hoepner L, Andrews H, Lopez-Pintado S, Quinn JW, Perera FP, Miller RL, Jacobson JS, Perzanowski MS. Neighborhood differences in exposure and sensitization to cockroach, mouse, dust mite, cat, and dog allergens in New York City. J Allergy Clin Immunol. 2011; 128:284-92. e7. [PubMed: 21536321]

4. Eder W, Ege MJ, von Mutius E. The asthma epidemic. N Engl J Med. 2006; 355:2226-35. [PubMed: 17124020]

5. Riedl M, Diaz-Sanchez D. Biology of diesel exhaust effects on respiratory function. J Allergy Clin Immunol. 2005; 115:221-8. quiz 9. [PubMed: 15696072]

6. Diaz-Sanchez D, Tsien A, Fleming J, Saxon A. Combined diesel exhaust particulate and ragweed allergen challenge markedly enhances human in vivo nasal ragweed-specific IgE and skews cytokine production to a T helper cell 2-type pattern. J Immunol. 1997; 158:2406-13. [PubMed: 9036991]

7. Diaz-Sanchez D, Garcia MP, Wang M, Jyrala M, Saxon A. Nasal challenge with diesel exhaust particles can induce sensitization to a neoallergen in the human mucosa. J Allergy Clin Immunol. 1999; 104:1183-8. [PubMed: 10588999]

8. Miller RL, Chew GL, Bell CA, Biedermann SA, Aggarwal M, Kinney PL, Tsai WY, Whyatt RM, Perera FP, Ford JG. Prenatal exposure, maternal sensitization, and sensitization in utero to indoor allergens in an inner-city cohort. Am J Respir Crit Care Med. 2001; 164:995-1001. [PubMed: 11587985]

9. Litonjua AA, Carey VJ, Burge HA, Weiss ST, Gold DR. Exposure to cockroach allergen in the home is associated with incident doctor-diagnosed asthma and recurrent wheezing. J Allergy Clin Immunol. 2001; 107:41-7. [PubMed: 11149989]

10. Tonne CC, Whyatt RM, Camann DE, Perera FP, Kinney PL. Predictors of personal polycyclic aromatic hydrocarbon exposures among pregnant minority women in New York City. Environ Health Perspect. 2004; 112:754-9. [PubMed: 15121521] 
11. Mastrangelo G, Fadda E, Marzia V. Polycyclic aromatic hydrocarbons and cancer in man. Environ Health Perspect. 1996; 104:1166-70. [PubMed: 8959405]

12. Perera FP. Environment and cancer: who are susceptible? Science. 1997; 278:1068-73. [PubMed: 9353182]

13. Miller RL, Garfinkel R, Horton M, Camann D, Perera FP, Whyatt RM, Kinney PL. Polycyclic aromatic hydrocarbons, environmental tobacco smoke, and respiratory symptoms in an inner-city birth cohort. Chest. 2004; 126:1071-8. [PubMed: 15486366]

14. Rosa MJ, Jung KH, Perzanowski MS, Kelvin EA, Darling KW, Camann DE, Chillrud SN, Whyatt RM, Kinney PL, Perera FP, Miller RL. Prenatal exposure to polycyclic aromatic hydrocarbons, environmental tobacco smoke and asthma. Respir Med. 2011; 105:869-76. [PubMed: 21163637]

15. Nadeau K, McDonald-Hyman C, Noth EM, Pratt B, Hammond SK, Balmes J, Tager I. Ambient air pollution impairs regulatory T-cell function in asthma. J Allergy Clin Immunol. 2010; 126:84552. e10. [PubMed: 20920773]

16. Hu X, Ji X, Srivastava SK, Xia H, Awasthi S, Nanduri B, Awasthi YC, Zimniak P, Singh SV. Mechanism of differential catalytic efficiency of two polymorphic forms of human glutathione Stransferase P1-1 in the glutathione conjugation of carcinogenic diol epoxide of chrysene. Arch Biochem Biophys. 1997; 345:32-8. [PubMed: 9281308]

17. Sundberg K, Johansson AS, Stenberg G, Widersten M, Seidel A, Mannervik B, Jernstrom B. Differences in the catalytic efficiencies of allelic variants of glutathione transferase P1-1 towards carcinogenic diol epoxides of polycyclic aromatic hydrocarbons. Carcinogenesis. 1998; 19:433-6. [PubMed: 9525277]

18. Kato S, Bowman ED, Harrington AM, Blomeke B, Shields PG. Human lung carcinogen-DNA adduct levels mediated by genetic polymorphisms in vivo. J Natl Cancer Inst. 1995; 87:902-7. [PubMed: 7666479]

19. Gilliland FD, Li YF, Saxon A, Diaz-Sanchez D. Effect of glutathione-S-transferase M1 and P1 genotypes on xenobiotic enhancement of allergic responses: randomised, placebo-controlled crossover study. Lancet. 2004; 363:119-25. [PubMed: 14726165]

20. Gilliland FD, Gauderman WJ, Vora H, Rappaport E, Dubeau L. Effects of glutathione-Stransferase M1, T1, and P1 on childhood lung function growth. Am J Respir Crit Care Med. 2002; 166:710-6. [PubMed: 12204870]

21. Gilliland FD, Li YF, Dubeau L, Berhane K, Avol E, McConnell R, Gauderman WJ, Peters JM. Effects of glutathione S-transferase M1, maternal smoking during pregnancy, and environmental tobacco smoke on asthma and wheezing in children. Am J Respir Crit Care Med. 2002; 166:45763. [PubMed: 12186820]

22. Melen E, Nyberg F, Lindgren CM, Berglind N, Zucchelli M, Nordling E, Hallberg J, Svartengren M, Morgenstern R, Kere J, Bellander T, Wickman M, Pershagen G. Interactions between glutathione S-transferase P1, tumor necrosis factor, and traffic-related air pollution for development of childhood allergic disease. Environ Health Perspect. 2008; 116:1077-84. [PubMed: 18709160]

23. Perzanowski MS, Miller RL, Tang D, Ali D, Garfinkel RS, Chew GL, Goldstein IF, Perera FP, Barr RG. Prenatal acetaminophen exposure and risk of wheeze at age 5 years in an urban lowincome cohort. Thorax. 2010; 65:118-23. [PubMed: 19850963]

24. Chew GL, Perzanowski MS, Miller RL, Correa JC, Hoepner LA, Jusino CM, Becker MG, Kinney PL. Distribution and determinants of mouse allergen exposure in low-income New York City apartments. Environ Health Perspect. 2003; 111:1348-51. [PubMed: 12896857]

25. Filep S, Tsay A, Vailes L, Gadermaier G, Ferreira F, Matsui E, King EM, Chapman MD. A multiallergen standard for the calibration of immunoassays: CREATE principles applied to eight purified allergens. Allergy. 2012; 67:235-41. [PubMed: 22092159]

26. Jung KH, Patel MM, Moors K, Kinney PL, Chillrud SN, Whyatt R, Hoepner L, Garfinkel R, Yan B, Ross J, Camann D, Perera FP, Miller RL. Effects of Heating Season on Residential Indoor and Outdoor Polycyclic Aromatic Hydrocarbons, Black Carbon, and Particulate Matter in an Urban Birth Cohort. Atmos Environ. 2010; 44:4545-52. [PubMed: 20938487]

27. Donohue KM, Al-alem U, Perzanowski MS, Chew GL, Johnson A, Divjan A, Kelvin EA, Hoepner LA, Perera FP, Miller RL. Anti-cockroach and anti-mouse IgE are associated with early wheeze 
and atopy in an inner-city birth cohort. J Allergy Clin Immunol. 2008; 122:914-20. [PubMed: 19000580]

28. Chang C, Gauvey-Kern K, Johnson A, Kelvin EA, Chew GL, Perera F, Miller RL. Cord blood versus age 5 mononuclear cell proliferation on IgE and asthma. Clin Mol Allergy. 2010; 8:11. [PubMed: 20684781]

29. Arand M, Muhlbauer R, Hengstler J, Jager E, Fuchs J, Winkler L, Oesch F. A multiplex polymerase chain reaction protocol for the simultaneous analysis of the glutathione S-transferase GSTM1 and GSTT1 polymorphisms. Anal Biochem. 1996; 236:184-6. [PubMed: 8619490]

30. Perzanowski MS, Chew GL, Divjan A, Johnson A, Goldstein IF, Garfinkel RS, Hoepner LA, Platts-Mills TA, Perera FP, Miller RL. Cat ownership is a risk factor for the development of anticat IgE but not current wheeze at age 5 years in an inner-city cohort. J Allergy Clin Immunol. 2008; 121:1047-52. [PubMed: 18395554]

31. Antens CJ, Oldenwening M, Wolse A, Gehring U, Smit HA, Aalberse RC, Kerkhof M, Gerritsen J, de Jongste JC, Brunekreef B. Repeated measurements of mite and pet allergen levels in house dust over a time period of 8 years. Clin Exp Allergy. 2006; 36:1525-31. [PubMed: 17177675]

32. Sporik R, Holgate ST, Platts-Mills TA, Cogswell JJ. Exposure to house-dust mite allergen (Der p I) and the development of asthma in childhood. A prospective study. N Engl J Med. 1990; 323:502-7. [PubMed: 2377175]

33. Lau S, Illi S, Sommerfeld C, Niggemann B, Bergmann R, von Mutius E, Wahn U. Early exposure to house-dust mite and cat allergens and development of childhood asthma: a cohort study. Multicentre Allergy Study Group. Lancet. 2000; 356:1392-7. [PubMed: 11052581]

34. Torrent M, Sunyer J, Munoz L, Cullinan P, Iturriaga MV, Figueroa C, Vall O, Taylor AN, Anto JM. Early-life domestic aeroallergen exposure and IgE sensitization at age 4 years. J Allergy Clin Immunol. 2006; 118:742-8. [PubMed: 16950296]

35. Heinrich J, Hoelscher B, Wjst M, Ritz B, Cyrys J, Wichmann H. Respiratory diseases and allergies in two polluted areas in East Germany. Environ Health Perspect. 1999; 107:53-62. [PubMed: 9872717]

36. Liu J, Ballaney M, Al-alem U, Quan C, Jin X, Perera F, Chen LC, Miller RL. Combined inhaled diesel exhaust particles and allergen exposure alter methylation of T helper genes and $\mathrm{IgE}$ production in vivo. Toxicol Sci. 2008; 102:76-81. [PubMed: 18042818]

37. Cornell AG, Chillrud SN, Mellins RB, Acosta LM, Miller RL, Quinn JW, Yan B, Divjan A, Olmedo OE, Lopez-Pintado S, Kinney PL, Perera FP, Jacobson JS, Goldstein IF, Rundle AG, Perzanowski MS. Domestic airborne black carbon and exhaled nitric oxide in children in NYC. J Expo Sci Environ Epidemiol. 2012; 22:258-66. [PubMed: 22377682]

38. Yoshida T, Yoshioka Y, Fujimura M, Yamashita K, Higashisaka K, Nakanishi R, Morishita Y, Kayamuro H, Nabeshi H, Nagano K, Abe Y, Kamada H, Tsunoda S, Yoshikawa T, Itoh N, Tsutsumi Y. Potential adjuvant effect of intranasal urban aerosols in mice through induction of dendritic cell maturation. Toxicol Lett. 2010; 199:383-8. [PubMed: 20934492]

39. Samuelsen M, Nygaard UC, Lovik M. Allergy adjuvant effect of particles from wood smoke and road traffic. Toxicology. 2008; 246:124-31. [PubMed: 18289765]

40. Porter M, Karp M, Killedar S, Bauer SM, Guo J, Williams D, Breysse P, Georas SN, Williams MA. Diesel-enriched particulate matter functionally activates human dendritic cells. Am J Respir Cell Mol Biol. 2007; 37:706-19. [PubMed: 17630318]

41. Jung KH, Yan B, Hsu S, Moors K, Chillrud SN, Whyatt RM, Perzanowski MS, Hoepner L, Goldstein IF, Zhang B, Camann D, Kinney PL, Perera FP, Miller RL. Repeated Exposure to Polycyclic Aromatic Hydrocarbons and Asthma: Effect of Seroatopy Ann Allergy. Asthma and Immunol. 2012; 109:249-54.

42. Bommel H, Li-Weber M, Serfling E, Duschl A. The environmental pollutant pyrene induces the production of IL-4. J Allergy Clin Immunol. 2000; 105:796-802. [PubMed: 10756232]

43. Bommel H, Haake M, Luft P, Horejs-Hoeck J, Hein H, Bartels J, Schauer C, Poschl U, Kracht M, Duschl A. The diesel exhaust component pyrene induces expression of IL-8 but not of eotaxin. Int Immunopharmacol. 2003; 3:1371-9. [PubMed: 12946434] 
44. Kimata H, Yoshida A, Ishioka C, Lindley I, Mikawa H. Interleukin 8 (IL-8) selectively inhibits immunoglobulin E production induced by IL-4 in human B cells. J Exp Med. 1992; 176:1227-31. [PubMed: 1383379]

45. Ginsberg G, Smolenski S, Hattis D, Guyton KZ, Johns DO, Sonawane B. Genetic Polymorphism in Glutathione Transferases (GST): Population distribution of GSTM1, T1, and P1 conjugating activity. J Toxicol Environ Health B Crit Rev. 2009; 12:389-439. [PubMed: 20183528]

46. Rojas M, Cascorbi I, Alexandrov K, Kriek E, Auburtin G, Mayer L, Kopp-Schneider A, Roots I, Bartsch H. Modulation of benzo[a]pyrene diolepoxide-DNA adduct levels in human white blood cells by CYP1A1, GSTM1 and GSTT1 polymorphism. Carcinogenesis. 2000; 21:35-41. [PubMed: 10607731]

47. Platts-Mills TA, Vervloet D, Thomas WR, Aalberse RC, Chapman MD. Indoor allergens and asthma: report of the Third International Workshop. J Allergy Clin Immunol. 1997; 100:S2-24. [PubMed: 9438476]

48. Chew GL, Correa JC, Perzanowski MS. Mouse and cockroach allergens in the dust and air in northeastern United States inner-city public high schools. Indoor Air. 2005; 15:228-34. [PubMed: 15982269]

49. Chew GL, Burge HA, Dockery DW, Muilenberg ML, Weiss ST, Gold DR. Limitations of a home characteristics questionnaire as a predictor of indoor allergen levels. Am J Respir Crit Care Med. 1998; 157:1536-41. [PubMed: 9603135]

50. Morgan WJ, Crain EF, Gruchalla RS, O’Connor GT, Kattan M, Evans R 3rd, Stout J, Malindzak G, Smartt E, Plaut M, Walter M, Vaughn B, Mitchell H. Results of a home-based environmental intervention among urban children with asthma. N Engl J Med. 2004; 351:1068-80. [PubMed: 15356304]

51. Kass D, McKelvey W, Carlton E, Hernandez M, Chew G, Nagle S, Garfinkel R, Clarke B, Tiven J, Espino C, Evans D. Effectiveness of an integrated pest management intervention in controlling cockroaches, mice, and allergens in New York City public housing. Environ Health Perspect. 2009; 117:1219-25. [PubMed: 19672400]

52. Seamonds, D.; Lowell, D.; Balon, T.; Leigh, R.; Silverman, I. The bottom of the barrel: How the dirtiest heating oil pollutes our air and harms our health. 2009. www.edf.org/dirtybuildings

53. Rundle A, Hoepner L, Hassoun A, Oberfield S, Freyer G, Holmes D, Reyes M, Quinn J, Camann D, Perera F, Whyatt R. Association of childhood obesity with maternal exposure to ambient air polycyclic aromatic hydrocarbons during pregnancy. Am J Epidemiol. 2012; 175:1163-72. [PubMed: 22505764]

54. Rosenstreich DL, Eggleston P, Kattan M, Baker D, Slavin RG, Gergen P, Mitchell H, McNiffMortimer K, Lynn H, Ownby D, Malveaux F. The role of cockroach allergy and exposure to cockroach allergen in causing morbidity among inner-city children with asthma. N Engl J Med. 1997; 336:1356-63. [PubMed: 9134876]

55. Rauh VA, Whyatt RM, Garfinkel R, Andrews H, Hoepner L, Reyes A, Diaz D, Camann D, Perera FP. Developmental effects of exposure to environmental tobacco smoke and material hardship among inner-city children. Neurotoxicol Teratol. 2004; 26:373-85. [PubMed: 15113599] 


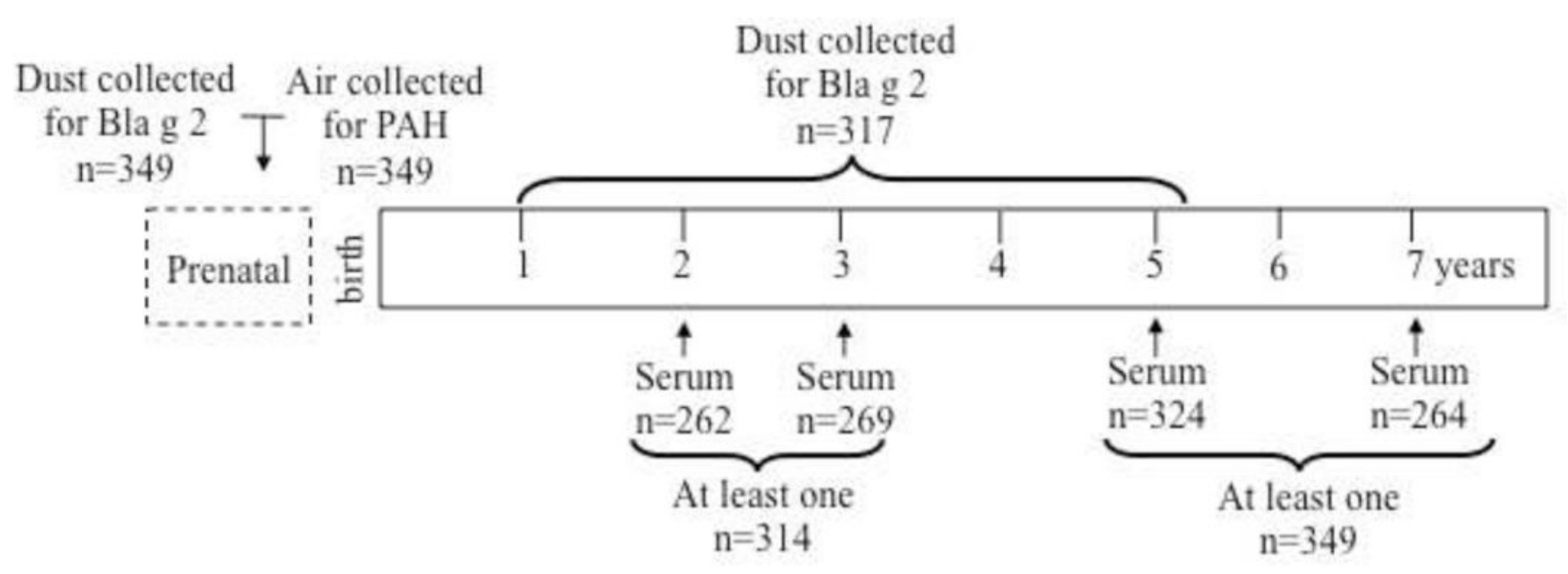

Figure 1. Overview of study and children included in analyses

Of the 727 children enrolled prenatally, analyses for the current study was restricted to the $\mathrm{n}$ = 349 who had valid measurements for prenatal Bla g2 and PAH and allergen specific IgE measured at age 5 and/or 7 . 


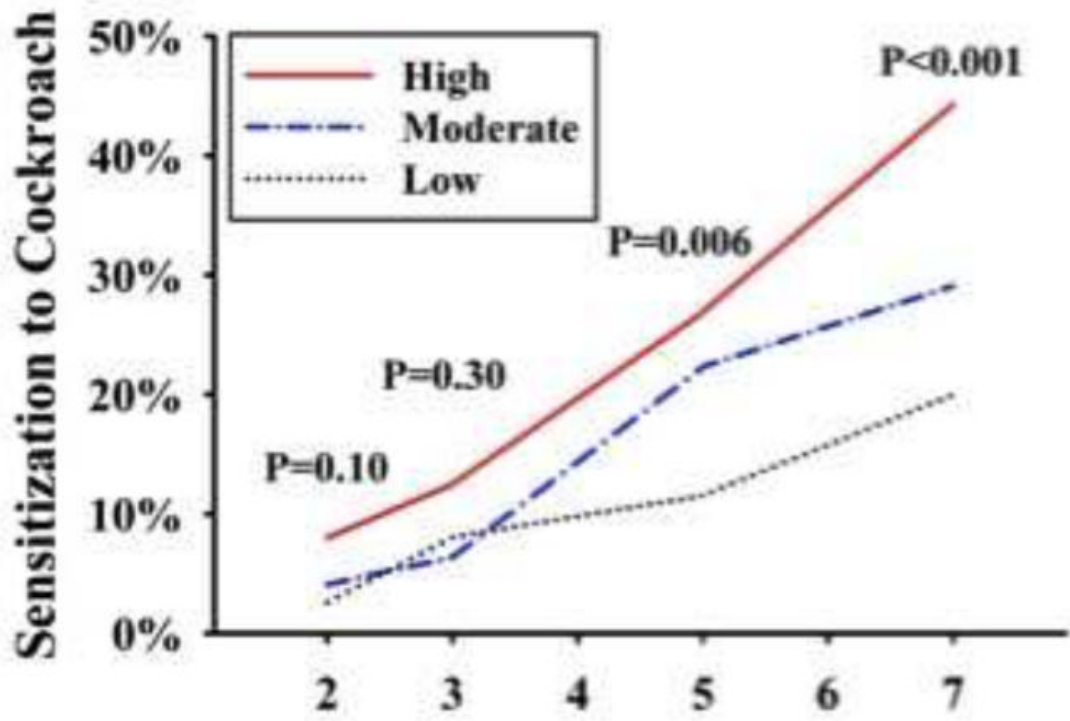

Age in years

Figure 2. Prevalence of sensitization to cockroach with tertiles of prenatal Bla g2 in kitchen dust Tertiles of Bla g2 were defined as follows: low $=<0.73 \mathrm{ng} / \mathrm{g}$, moderate $=0.73-772 \mathrm{ng} / \mathrm{g}$, high $=>772 \mathrm{ng} / \mathrm{g}$. Sensitization was defined as $\geq 0.35 \mathrm{IU} / \mathrm{ml} \mathrm{IgE}$ to cockroach. 


\section{A. Lower prenatal $\sum_{8} \mathbf{P A H}_{\text {nonvolatile }}$}

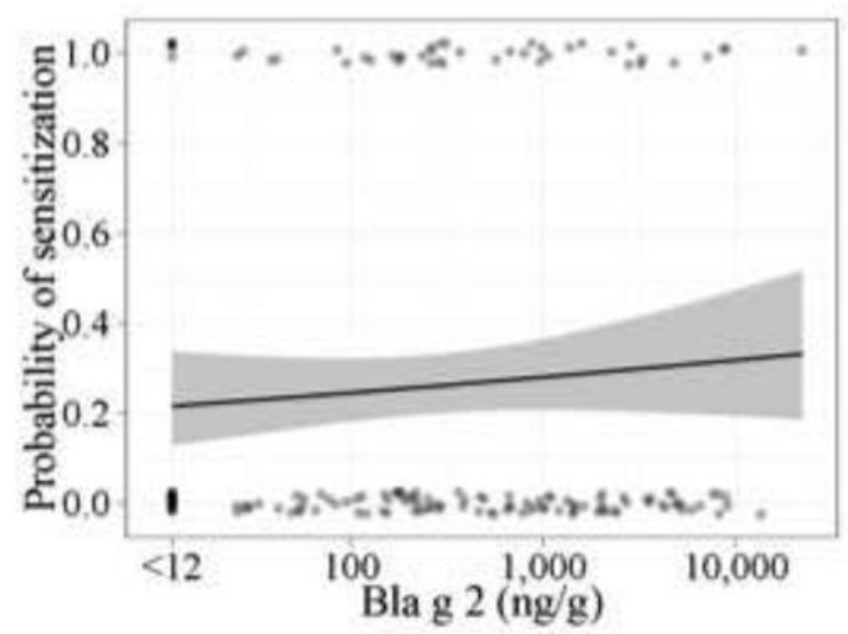

B. Higher prenatal $\sum_{8} \mathbf{P A H}_{\text {nonvolatile }}$

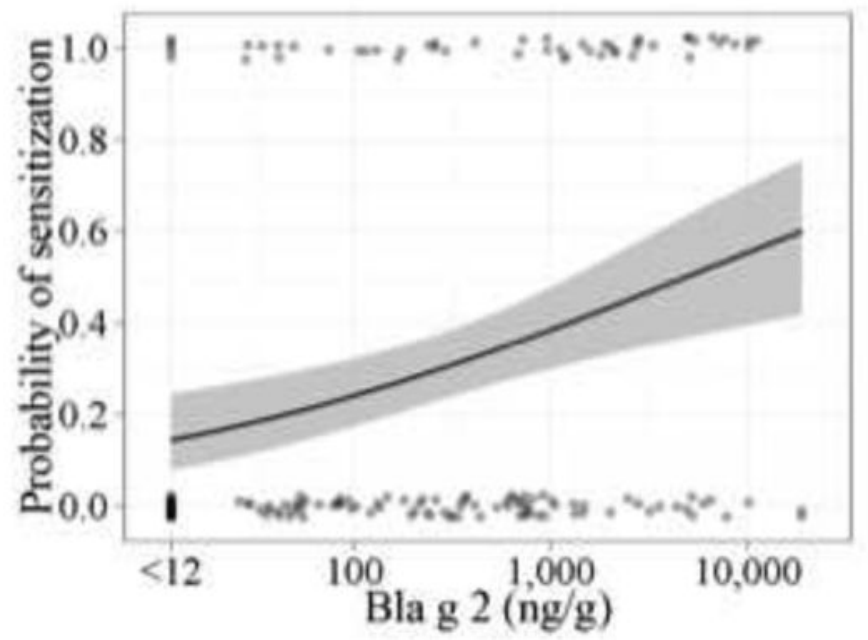

Figure 3. Probability of sensitization to cockroach at age 5-7 with prenatal Bla g2 exposure among children with (A) lower and (B) higher prenatal airborne $\Sigma_{\mathbf{8}} \mathbf{P A H _ { n o n v o l a t i l e }}$ $\Sigma_{8} \mathrm{PAH}_{\text {nonvolatile }}$ concentrations were dichotomized at the median $\left(2.25 \mathrm{ng} / \mathrm{m}^{3}\right)$. Unadjusted logistic regression lines are depicted with $95 \%$ C.I. in gray (A. $\mathrm{P}=0.34$ and $\mathrm{B} . \mathrm{P}<0.001$ ). 


\section{A. Lower $\sum_{8} \mathrm{PAH}_{\text {nanvatile, }}$ GSTM present}

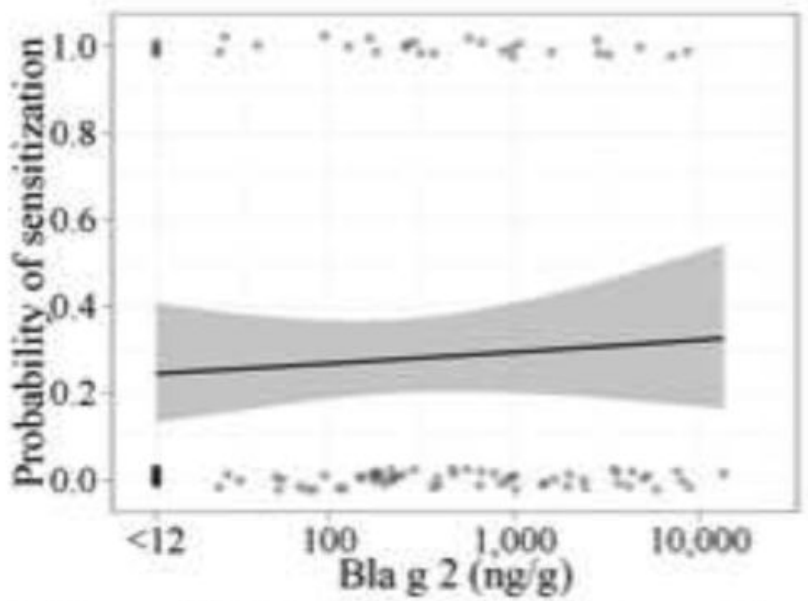

C. Lower $\sum_{8} \mathrm{PAH}_{\text {nonvatatile, }}$ GSTM present

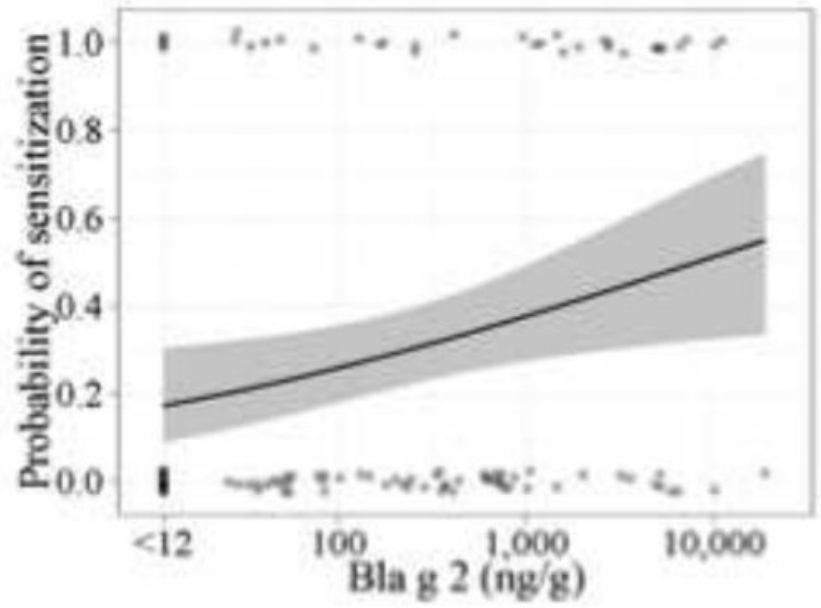

B. Lower $\sum_{8}$ PAH $_{\text {nanvulatile }}$ GSTM null

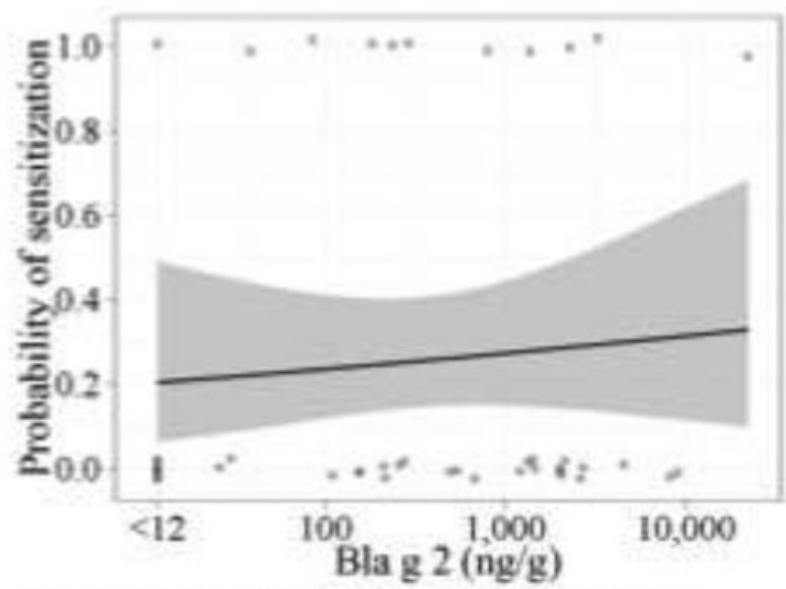

D. Lower $\sum_{s} \mathrm{PAH}_{\text {neavolatile, }}$ GSTM null

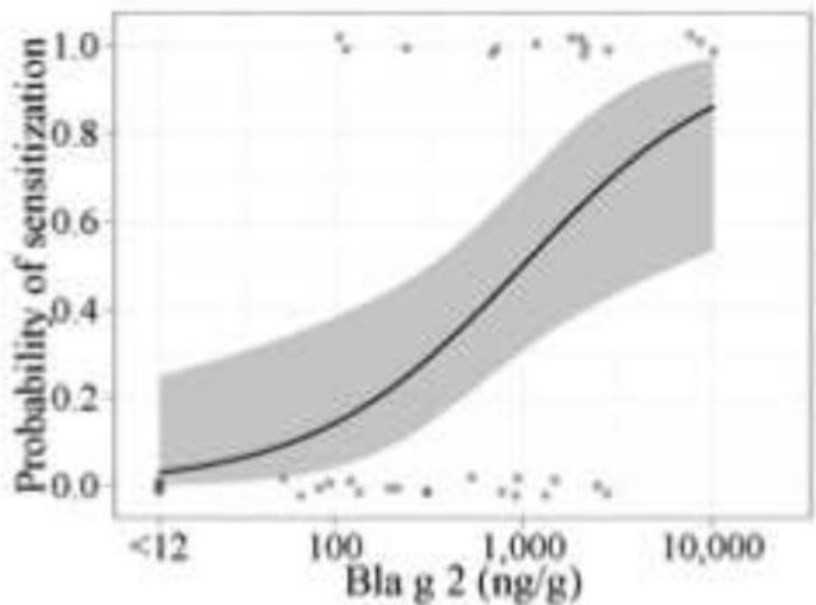

Figure 4. Probability of sensitization to cockroach at age 5-7 with prenatal Bla g2 exposure stratified by prenatal $\Sigma_{\mathbf{8}} \mathbf{P A H}_{\text {nonvolatile }}$ exposure and GSTM polymorphisms $\Sigma_{8} \mathrm{PAH}_{\text {nonvolatile }}$ concentrations were dichotomized at the median $\left(2.25 \mathrm{ng} / \mathrm{m}^{3}\right)$. Unadjusted logistic regression lines are depicted with $95 \%$ C.I. in gray $(\mathrm{A} . \mathrm{P}=0.43$; $\mathrm{B}$. $\mathrm{P}=0.60 ; \mathrm{C} . \mathrm{P}=$ 0.017 ; D. $\mathrm{P}=0.005)$ 


\section{Table I}

Demographics of mother.

\begin{tabular}{|c|c|c|}
\hline & Age, mean $(\mathrm{SD})^{\dagger}$ & $25.2(5.0)$ \\
\hline \multirow[t]{2}{*}{$\underline{\text { Racelethnicity }}$} & African-American, $\mathrm{n}(\%)^{\dagger}$ & $135 / 349(38.7)$ \\
\hline & Dominican, n (\%) & $214 / 349(61.3)$ \\
\hline \multirow[t]{2}{*}{$\underline{\text { Self-reported health }}$} & Asthma, n $(\%)^{*}$ & $79 / 349(22.6)$ \\
\hline & 'Allergy', n $(\%)^{\mathcal{\xi}}$ & $149 / 346(42.7)$ \\
\hline \multirow[t]{3}{*}{$\underline{\text { Socio-demographics }}$} & No high school degree, $\mathrm{n}(\%)^{\dagger}$ & $132 / 344(38.1)$ \\
\hline & Receiving Medicaid, $\mathrm{n}(\%)^{\dagger}$ & $325 / 349(93.1)$ \\
\hline & Material hardship last 6 months, $\mathrm{n}(\%)^{q /}$ & $164 / 349(47.0)$ \\
\hline \multirow[t]{5}{*}{ Domestic environment } & Smoker in home, $\mathrm{n}(\%)^{\dagger}$ & $119 / 349(34.1)$ \\
\hline & Cockroach sightings common,n (\%) & $153 / 319(48.0)$ \\
\hline & Mouse sightings common,n (\%)@ & $67 / 319(21.0)$ \\
\hline & Cat in home, $\mathrm{n}(\%)^{\dagger}$ & $36 / 348(10.3)$ \\
\hline & Dog in home, $\mathrm{n}(\%)^{\dagger}$ & $15 / 348(4.3)$ \\
\hline
\end{tabular}

Footnotes for Table I.

${ }^{\dagger}$ Reported on the prenatal questionnaire

Mother reported either during pregnancy or on a questionnaire 3 months after the child was born that she had asthma.

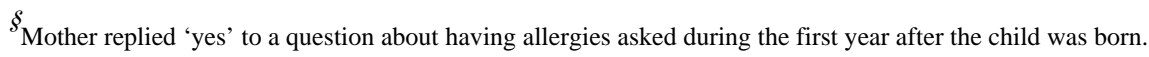

II care or that gas/electricity was suspended because of bill non-payment. (55)

${ }^{\circledR}$ Cockroaches or mice seen at least weekly. 
Table II

Adjusted relative risks (RR) ${ }^{\dagger}$ for sensitization to cockroach at age 5-7 with prenatal kitchen Bla g2 concentration, stratified by potential effect modifying variables.

\begin{tabular}{|c|c|c|c|}
\hline Potential effect modifier ${ }^{*}$ & & n & RR $\left[95 \%\right.$ CI] for sensitization with Bla $\mathrm{g}^{\dagger}$ \\
\hline & Unstratified & 349 & $1.15[1.07-1.25]^{* *}$ \\
\hline \multirow[t]{2}{*}{ Sex of child } & Male & 166 & $1.15[1.02-1.29]^{*}$ \\
\hline & Female & 183 & $1.17[1.05-1.31]^{* *}$ \\
\hline \multirow[t]{2}{*}{ Race/ethnicity } & African-American & 135 & $1.21[1.07-1.37]^{* *}$ \\
\hline & Dominican & 214 & $1.11[0.99-1.23]$ \\
\hline \multirow[t]{2}{*}{ Maternal asthma } & No & 270 & $1.17[1.07-1.28]^{* * *}$ \\
\hline & Yes & 79 & $1.11[0.94-1.31]$ \\
\hline \multirow[t]{2}{*}{ Maternal 'allergy’ $\$$} & No & 197 & $1.18[1.07-1.31]^{* * *}$ \\
\hline & Yes & 149 & $1.12[0.98-1.27]$ \\
\hline \multirow[t]{2}{*}{ High school degree } & No & 132 & $1.12[0.99-1.26]$ \\
\hline & Yes & 212 & $1.16[1.05-1.29]^{* *}$ \\
\hline \multirow[t]{2}{*}{ Material hardship $\mathcal{S}$} & No & 185 & $1.13[1.02-1.27]^{*}$ \\
\hline & Yes & 170 & $1.19[1.05-1.34]^{* *}$ \\
\hline \multirow[t]{2}{*}{ Environmental tobacco smoke } & No & 230 & $1.16[1.04-1.29]^{* *}$ \\
\hline & Yes & 119 & $1.14[1.01-1.29]^{*}$ \\
\hline \multirow[t]{2}{*}{ Birth order of child } & First born & 167 & $1.19[1.06-1.34]^{* *}$ \\
\hline & Second or later & 182 & $1.13[1.02-1.25]^{*}$ \\
\hline
\end{tabular}

Footnotes for Table II.

* $\mathrm{P}<0.05$,

*** $\mathrm{P}<0.01$

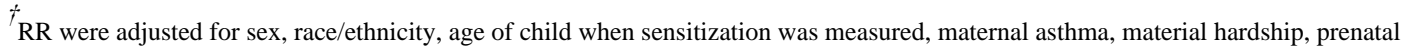
environmental tobacco smoke and older siblings. Variables tested in stratification were removed from the models for which they were stratified. Effect modification was tested with a multiplicative interaction term ('variable' by Bla g2) in the fully adjusted model. All interaction terms for the variables in the table had a $\mathrm{P}$ value $>0.20$.

"Mother replied 'yes' to a question about having allergies asked during the first year after the child was born.

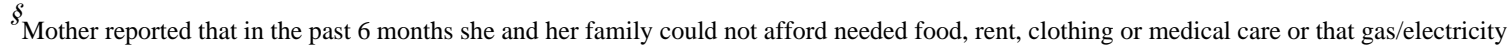
was suspended because of bill non-payment.(55) 